\title{
PENGARUH SISTEM MANAJEMEN SDM BERBASIS KOMPETENSI DAN PENILAIAN PRESTASI KERA TERHADAP KINERJA KARYAWAN PADA PT. INDUCOMP DEWATA DENPASAR
}

\author{
Amirah \\ Ni Made Yudhaningsih \\ Jurusan Manajemen, Fakultas Ekonomi, Universitas Mahendradatta \\ Jl. Ken Arok No 12, Peguyangan Denpasar Utara, Bali 80115 \\ Email :amira.rauter@gmail.com
}

\begin{abstract}
ABSTRAK-Penelitian ini bertujuan untuk mengetahui pengaruh sistem manajemen SDM berbasis kompetensi dan penilaian prestasi kerja terhadap kinerja PT. Inducomp Dewata Denpasar. Populasi dalam penelitian ini adalah karyawan bagian produksi sebanyak 270 dengan sampel sebanyak 73 responden.Sampel diambil dengan menggunakan teknik simple random sampling. Metode yang digunakan dalam menganalisa data adalah uji validitas dan reliabilitas, analisis regresi berganda dan uji t serta uji f. Hasil penelitian secara parsial menunjukkan tidak ada pengaruh dari variabel sistem manajemen SDM berbasis kompetensi $\left(\mathrm{X}_{1}\right)$ terhadap kinerja karyawan (Y) PT. Inducomp Dewata Denpasar. Namun, ada pengaruh positif dan signifikan dari variabel penilaian prestasi kerja $\left(\mathrm{X}_{2}\right)$ terhadap kinerja karyawan (Y) PT. Inducomp Dewata. Berdasarkan hasil penelitian secara simultan, ada pengaruh yang signifikan dari variabel sistem Manajemen SDM berbasis kompetensi dan penilaian prestasi kerja terhadap kinerja karyawan PT. Inducomp Dewata Denpasar dengan nilai f hitung $>\mathrm{f}$ tabel $(26,991>3,13)$ dan sig $(0,000)$. Hendaknya pihak PT. Inducomp Dewata Denpasar meningkatkan sistem penilaian prestasi kerja dengan mengevaluasi hasil penilaian kinerja karyawan secara berkala untuk mengetahui akan kebutuhan pelatihan dan pengembangan karyawan serta memotivasi karyawan agar menghasilkan kinerja karyawan yang lebih baik lagi kedepannya.
\end{abstract}

\section{Kata kunci : sistem manajemen SDM berbasis kompetensi, penilaian prestasi kerja, kinerja}

ABSTRACT - This research aims to find out the impact of competency-based human resource management and work performance appraisal towards the employees' performance of PT. Inducomp Dewata. As much as 270 employees became the population of this analysis and it took only 73 respondents as the sample. Simple random sampling technique used as the tool to collect the samples. The method used to analyze the data were validity check, reliability check, multiple regression analysis and t check and f check. Partial research result shows that there is no effect of competency-based human resource management system variable $\left(X_{1}\right)$ towards employees' performance variable (Y) of PT. Inducomp Dewata Denpasar. On the other hand, there is a positive yet significance effect of the variable from work performance appraisal $\left(X_{2}\right)$ towards employees' performance $(Y)$ PT. Inducomp

Amirah

Ni Made Yudhaningsih 
Dewata. According to simulants research results, it shows the is a significance effect from the variable of competency-based human resource management system and the variable of work performance appraisal towards employees' performance of PT. Inducomp Dewata Denapasar with f-value > f-table $(26.991>3.13)$ and sig (0.000). PT. Inducomp Dewata should improve the work performance appraisal system and evaluate the work performance assessment regularly in order to know the needs of employees' training and development as well as motivated the employees', which will produce the better work performance of the employees' in the future.

Keywords: competencey-based human resource management system, work performance appraisal, performance

\section{PENDAHULUAN}

Latar Belakang

Semakin

pertumbuhanekonomi

mengakibatkan semakinkompleksnya masalah yang adadidalam suatu perusahaan,mendapatkan sumber daya manusiayang kompeten dan ahli dibidangnyaadalah salah satunya, banyak konsepdilakukan untuk mendapatkankaryawan yang memiliki keahlian danprofesionalisme tinggi dalam bekerja. Sumber daya manusia merupakanfaktor penting bagi setiap organisasi,sebab tanpa sumber daya manusiatujuan dan sasaran organisasi tidakakan tercapai sesuai yang direncanakan.Oleh karena itu peranan sumber dayamanusia sangat penting dalam setiaporganisasi.Pentingnya peranan sumberdaya manusia bagi setiap organisasidiharapkan dapat meningkatkan kinerjakaryawan, untuk itu sumber dayamanusia perlu memiliki skill atauketerampilan yang handal dalammenangani setiap pekerjaan, sebabdengan adanya skil yang handal makasecara langsung dapat meningkatkankinerja karyawan.

MenurutArmstrong dan Baron dalamWibowo (2009:99), faktorfaktoryang mempengaruhi kinerja adalahpersonal factors yang ditentukanoleh tingkat keterampilan, kompetensiyang dimiliki, motivasi, komitmenindividu, leadership factor, teamfactors, system factors, dancontextual/situasional factors. Kompetensi merupakan salah satu factor yang mempengaruhi kinerja karyawan.Menurut Spencer and Spencer (2003:9) kompetensi adalah karakteristik yang mendasari seseorang yang berkaitan dengan standar kriteria kinerja yang efektif dan atau superior di tempat kerja pada situasi tertentu.Kompetensi menggambarkan tingkat pengetahuan, keterampilan dan tingkah laku yang dimiliki karyawan dalam melaksanakan tugasnya yang efektif dan efisien.

Salah satu cara yang dilakukan oleh perusahaan agar dapat menghasilkan sumber dayayang berkompeten adalah denganmelakukan penilaian prestasi kerjaterhadap para karyawan yang 
adadalam perusahaan yang bersangkutan.Tujuan pokok dari penilaian prestasikerja karyawan adalah untukmenghasilkan informasi yang akurattentang perilaku dan kinerja parakaryawan yang ada didalam perusahaan.Sementara tujuan lainnya adalahsebagai bahan evaluasi serta sebagaibahan pertimbangan untuk melakukankebijakan selanjutnya.

PT. Inducomp Dewata merupakan salah satu perusahaan yang bergerak di bidang jasa perakitan komponen induktor yang tentunya memiliki karyawan yang jumlahnya tergolong tidak sedikit.Ada permasalahan yang dialami di beberapa proses produksi yaitu tidak tercapainya target yang telah ditentukan perusahaan oleh karyawan produksi sehingga membuat jumlah hasil produksi/output tidak sesuai dengan yang telah direncanakan yang tentunya berpengaruh terhadap jumlah dan jadwal pengiriman ke customer.Selain itu, berdasarkan wawancara tidak terstruktur yang telah dilakukan, didapat banyak karyawan yang meremehkan sikap dan kedisplinan mereka dan mengira bahwa output yang dihasilkan sudah cukup memberikan timbal balik terhadap perusahaan. Padahal, dengan perilaku yang baik dan ditunjang dengan kedisiplinan, secara tidak langsung akan menciptakan lingkungan perusahaan yang berbudaya. Perusahaan juga meyakini, bahwa karyawan yang baik dalam segi prilaku dan disiplin akan mempengaruhi kinerja mereka di perusahaan, sehingga mampu membantu perusahaan untuk mencapai tujuan perusahaan.

\section{Landasan Teori}

Menurut Wibowo (2016:271) kompetensi adalah suatu kemampuan untuk melaksanakan atau melakukan suatu pekerjaan atau tugas yang dilandasi atas keterampilan dan pengetahuan serta didukung oleh sikap kerja yang dituntut oleh pekerjaan tersebut.Dengan demikian, kompetensi menunjukkan keterampilan atau pengetahuan yang dicirikan oleh profesionalisme dalam suatu bidang tertentu sebagai sesuatu yang terpenting, sebagai unggulan bidang tersebut.Menurut Hutapea dan Nurianna (2008;16-19) kompetensi dalam

organisasi atau perusahaan pada umumnya bertujuan untuk pembentukan pekerjaan (job design, evaluasi pekerjaan (job evaluation, rekrutmen dan seleksi (recruitment and selection), pembentukan dan pengembangan organisasi (organization design anddevelopment), membentuk dan memperkuat nilai dan budaya perusahaan (companyculture), pembelajaran organisasi (organizational learning), manajemen karier dan penilaian potensi karyawan (career management \&employee's assessment), sistem imbal jasa (reward system).

Penilaian kinerja kerja menurut Hasibuan (2012:87) yaitu menilai rasio hasil kerja nyata dengan standar kualitas maupun kuantitas yang dihasilkan setiap karyawan.Penilaian prestasi kerja memungkinkan para karyawan untuk mengetahuibagaimana prestasi kerja mereka, dan sejauh mana hasil kerja 
mereka dinilai olehatasan.Kegiatan penilaian ini dapat memperbaiki keputusan-keputusan personaliadan memberi umpan balik kepada karyawan dalam pelaksanaan kerja mereka. Halini akan dapat memotivasi mereka untuk kemajuankemajuan mereka di masayang akan datang.

\section{Tujuan dan Hipotesis Penelitian}

Tujuan penelitian ini untuk mengetahui pengaruh sistem manajemen SDM berbasis kompetensi dan penilaian prestasi kerja terhadap kinerja karyawan pada PT. Inducomp Dewata.Adapun hipotesis dalam penelitian ini yaitu :

1. Diduga sistem manajemen SDM berbasis kompetensi berpengaruh terhadap kinerja karyawa PT. Inducomp Dewata.

2. Diduga sistem manajemen SDM berbasis penilaian prestasi kerja berpengaruh terhadap kinerja karyawan PT. Inducomp Dewata.

3. Diduga sistem manajemen SDM berbasis kompetensi dan penilaian prestasi kerja berpengaruh secara simultan terhadap kinerja karyawan PT. Inducomp Dewata.

\section{METODE}

Populasi dalam penelitian ini adalah pegawai Bagian Produksi PT. Inducomp Dewata sebanyak 270 karyawan, dengan jumlah sampel 73 responden. Pengambilan sampel dalam penelitian ini menggunakan metode Simple Random Sampling.Metode yang digunakan dalam menganalisa data adalah uji validitas dan reliabilitas, analisis regresi berganda dan uji $t$ serta uji $f$ dan koefisien
determinasi.Jenis dan sumber data Sumber data yang digunakan dalam penelitian ini adalah Data Primer dan sekunder.Data primer yang digunakan dalam penelitian ini diperoleh dari kuesioner yang diisi oleh 73 responden. Kuesioner yang dibagikan kepada responden tersebut meliputi identitas serta tanggapan dari responden terhadap sistem manajemen SDM berbasis kompetensi dan penilaian prestasi kerja serta kinerja karyawan. Data sekunder yang digunakan dalam penelitian ini antara lain mengenai sejarah singkat PT Inducomp Dewata dan data-data lain yang mendukung penelitian.

\section{HASIL PENELITIAN}

\section{Hasil Uji Validitas}

Uji validitas yaitu suatu uji dimana jika suatu instrument memenuhi kriteria $r$ hitung $>r$ tabel maka instrument tersebut dinyatakan valid atau layak dijadikan penelitian.Semua item soalmenghasilkan nilai rhitung lebih dari rtabel dengan $N=73$ dan taraf signifikansi $5 \%$ yaitu rtabel $=0.235$ sehingga semua item soal variabel sistem manajemen SDM berbasis kompetensi $\left(\mathrm{X}_{1}\right)$ dapat dikatakan valid dan dapat digunakan untuk penelitian.

\section{Hasil Uji Reliabilitas}

Uji reliabilitas dilakukan dengan melihat hasil uji statistik Alpha Cronbach.Suatu instrument dikatakan reliable, jika instrument tersebut memiliki nilai Alpha Cronbach lebih dari 0,60. 
Uji Reliabilitas

\begin{tabular}{|l|c|c|c|c|}
\hline \multicolumn{1}{|c|}{ Reliability Statistics } \\
\hline Variabel & Cronbach's Alpha & $\begin{array}{c}r \\
\text { Tabel }\end{array}$ & $\begin{array}{c}\text { Batas Minimun } \\
\text { Cronbach's } \\
\text { Alpha }\end{array}$ & Keterangan \\
\hline Kompetensi & 0,701 & & 0,60 & Reliabel \\
\cline { 1 - 2 } Penilaian prestasi Kerja & 0,846 & 0,235 & \\
\cline { 1 - 2 } Kinerja Karyawan & 0,727 & & \\
\hline
\end{tabular}

Sumber : Data Primer Diolah, 2019

Pada tabel 1 menunjukkan nilai Alpha Cronbach's dari ketiga variabel menunjukkan lebih besar dari 0,60. Maka kuesioner secara keseluruhan dapat dikatakan reliable.

\section{Hasil Uji Regresi Linier Berganda}

Dalam penelitian ini analisis regresi berganda digunakan untuk melihat pengaruh antara sistem manajemen sdm berbasis kompetensi, dan penilaian prestasi kerja secara bersama-sama terhadap kinerja karyawan, digunakan analisa regresi berganda dengan bantuan program SPSS ver 23, hasil seperti termuat pada tabel di bawah ini :

Tabel 2

Hasil Uji Regresi Linier Berganda

\begin{tabular}{|c|c|c|c|c|c|c|}
\hline \multicolumn{7}{|c|}{ Coefficients $^{\mathbf{a}}$} \\
\hline & \multirow{2}{*}{ Model } & \multicolumn{2}{|c|}{$\begin{array}{c}\text { Unstandardized } \\
\text { Coefficients } \\
\end{array}$} & \multirow{2}{*}{$\begin{array}{c}\begin{array}{c}\text { Standardized } \\
\text { Coefficients }\end{array} \\
\text { Beta }\end{array}$} & \multirow[b]{2}{*}{$\mathrm{t}$} & \multirow{2}{*}{ Sig. } \\
\hline & & $\mathrm{B}$ & $\begin{array}{l}\text { Std. } \\
\text { Error }\end{array}$ & & & \\
\hline \multirow{3}{*}{1} & (Constant) & 16,350 & 4,652 & & 3,515 &, 001 \\
\hline & $\begin{array}{l}\text { Kompetensi } \\
\text { (X1) }\end{array}$ &,- 132 & ,124 &,- 101 & $\begin{array}{c}- \\
1,066\end{array}$ & ,290 \\
\hline & $\begin{array}{c}\text { Penilaian } \\
\text { Prestasi } \\
\text { Kerja (X2) }\end{array}$ & ,698 & ,097 & ,686 & 7,214 &, 000 \\
\hline
\end{tabular}

a. Dependent Variable: Kinerja Karyawan (Y)

Sumber : Data Primer Diolah, 2019 
Dari data yang terlihat pada tabel 2 dapat diketahui bahwa nilai konstanta regresi linear berganda $\mathbf{1 6 , 3 5 0}$ dengan nilai koefisien regresi variabel kompetensi $\mathbf{- 0 , 1 3 2}$, nilai koefisien regresi penilaian prestasi kerja $\mathbf{0 , 6 9 8}$. Maka dengan mengacu pada rumus persamaan regresi linear berganda $\hat{Y}$ $=\mathrm{a}+\mathrm{b} 1 . \mathrm{X} 1+\mathrm{b} 2 . \mathrm{X} 2$ dapat dibentuk persamaan regresi linear berganda sebagai berikut :

$$
\begin{gathered}
\hat{\mathbf{Y}}=16,350+(-0,132) \cdot \mathrm{X} 1+ \\
\text { 0,698.X2 }
\end{gathered}
$$

Dimana :

$\mathrm{Y}=$ Kinerja karyawan

$\mathrm{X} 1=$ Kompetensi

$\mathrm{X} 2$ = Penilaian prestasi kerja

Kebermaknaan dari persamaan regresi linear berganda di atas mengandung implikasi :

- Konstanta 16,350 mengandung arti apabila variabel kompetensi dan penilaian prestasi kerja tidak ada $\left(X_{1}\right.$ dan $\left.X_{2}=0\right)$, maka kinerja karyawan berada pada angka 16,350 .

- Koefisien regresi $X_{1}$ (sistem manajemen SDM berbasis kompetensi) - 0,132 mengandung arti bahwa setiap penambahan satu poin variabel sistem manajemen SDM berbasis kompetensi tidak memberi pengaruh meningkatkan kinerja karyawan.

- Koefisien regresi $X_{2}$ (penilaian prestasi kerja) 0,698 mengandung arti bahwa setiap penambahan satu poin variabel penilaian prestasi kerja akan meningkatkan kinerja karyawan sebesar 0,698 kali.

Jika terjadi peningkatan satu poin atas kompetensi dan penilaian prestasi kerja secara bersama-sama maka kinerja karyawan akan mengalami peningkatan sebesar ($0,132+0,698)=\mathbf{0 , 5 6 6}$ kali. Selanjutnya untuk mengukur tingkat nyata pengaruh variabel sistem manajemen SDM berbasis kompetensi dan penilaian prestasi kerja secara bersama-sama terhadap kinerja karyawan, dilakukan uji F.

\section{Hasil Uji F}

Dengan bantuan tabel Anova hasil dari pengolahan data dengan program SPSS versi 23 diperoleh data sebagai berikut :

Tabel 3

Hasil Uji F

ANOVA $^{\mathrm{a}}$

\begin{tabular}{|l|l|r|r|r|r|r|}
\hline \multicolumn{2}{|l|}{ Model } & $\begin{array}{c}\text { Sum of } \\
\text { Squares }\end{array}$ & df & $\begin{array}{c}\text { Mean } \\
\text { Square }\end{array}$ & F & Sig. \\
\hline \multirow{2}{*}{1} & Regression & 465,930 & 2 & 232,965 & 26,991 &, $000^{\mathrm{b}}$ \\
\cline { 2 - 7 } & Residual & 604,179 & 70 & 8,631 & & \\
\cline { 2 - 7 } & Total & 1070,110 & 72 & & & \\
\hline
\end{tabular}

a. Dependent Variable: Kinerja Karyawan (Y)

b. Predictors: (Constant), Penilaian Prestasi Kerja (X2), Kompetensi (X1)

Sumber : Data Primer Diolah, 2019 
Hasil uji-f dikaitkan dengan hipotesis ketiga yang diajukan dalam penelitian ini yaitu :

Ho : $\beta_{3},<0$ : menunjukkan tidak terdapat pengaruh antara sistem manajemen SDM berbasis kopetensi dan penilaian presatsi kerja terhadap kinerja karyawan pada PT. Inducomp Dewata.

$\mathrm{H}_{1}: \beta_{3}>0$ : menunjukkan terdapat pengaruh antara sistem manajemen SDM berbasis kopetensi dan penilaian prestasi kerja terhadap kinerja karyawan pada PT. Inducomp Dewata.

Kriteria pengujian nilai F-hitung terhadap F-tabel adalah :

- Jika nilai F-hitung < F-tabel maka Ho diterima dan $\mathrm{H} 1$ ditolak

- Jika nilai F-hitung > F-tabel maka H0 ditolak dan $\mathrm{H} 1$ diterima

Berdasarkan data tabel di atas diperoleh F-hitung sebesar 26,991 dan sig 0,000. F-tabel pada taraf $\alpha=$ 0.05, df $1=$ (jumlah variabel independen $=2)$ dan df $2(\mathrm{n}-\mathrm{k}-1=$ $73-2-1=70$ ), maka nilai $\mathrm{F}$ tabel $=$ $3,13 \mathrm{Hal}$ ini berarti F-hitung $>\mathrm{F}$ tabel $(\mathbf{2 6 , 9 9 1}>\mathbf{3 , 1 3})$ dan sig $<0,05(\mathbf{0 , 0 0 0}$ $<\mathbf{0 , 0 5}$ ), maka hipotesis $H_{1}$ dapat diterima.

Dalam hal ini dapat dikatakan bahwa variabel sistem manajemen sumber daya manusia dan penilaian prestasi kerja secara bersama-sama berpengaruh secara signifikan terhadap kinerja karyawan, sehingga kedua variabel independen tersebut dapat digunakan untuk mengestimasi atau memprediksi variabel kinerja karyawan.

\section{Koefisien Determinasi}

Uji koefisien determinasi digunakan untuk mengukur ketepatan dari model analisis yang dibuat.Nilai koefisien determinasi merupakan alat untuk mengukur besarnya sumbangan dari variabel bebas yang diteliti terhadap variasi variabel terikat. Adapun hasil koefisien determinasi masing-masing variabel sebagai berikut:

Tabel 4

Hasil Uji Koefisien Determinasi Model Summary

\begin{tabular}{|c|c|c|c|c|}
\hline Model & $\mathrm{R}$ & $\begin{array}{c}\mathrm{R} \\
\text { Square }\end{array}$ & $\begin{array}{c}\text { Adjusted } \mathrm{R} \\
\text { Square }\end{array}$ & $\begin{array}{c}\text { Std. Error of the } \\
\text { Estimate }\end{array}$ \\
\hline 1 &, $660^{\mathrm{a}}$ &, 435 &, 419 & 2,938 \\
\hline
\end{tabular}

a. Predictors: (Constant), Penilaian Prestasi Kerja (X2), Kompetensi (X1)

Sumber : Data Primer Diolah, 2019 
Jurnal Satyagraha, Vol. 02, No. 02, Agustus 2019 - Januari 2020 ISSN :2620-6358

Dari tabel model summary di atas dapat diketahui bahwa nilai $\mathrm{R}$ adalah 0,660 , sedangkan nilai R2 sebesar 0,435. Oleh karena uji koefisien determinasi berganda ini diperoleh dari perhitungan regresi linear berganda, maka koesiein determinasi sebesar $\mathbf{0 , 4 3 5}$ atau $\mathrm{R}^{2}$ x $100 \%$ sebesar $\mathbf{4 3 , 5 0 \%}$. Kebermaknaan dari nilai tersebut memiliki implikasi bahwa variabel sistem manajemen sumber daya manusia berbasis kompetensi dan penilaian prestasi kerja terhadap kinerja karyawan pada PT. Inducomp Dewata Denpasar sebesar $43,50 \%$ yang didominasi oleh variabel $\mathrm{X}_{2}$ yaitu penilaian prestasi kerja dan sisanya $56,60 \%$ dipengaruhi oleh variabel variabel lain di luar model yang dimasukkan dan tidak diteliti dalam penelitian ini.

\section{HASIL PENELITIAN}

1. Persepsi sistem manajemen SDM berbasis kompetensi dari persepsi para responden yang diperoleh melalui hasil angket kuesioner, menunjukkan bahwa sistem manajemen SDM berbasis kompetensi diterima dengan baik. Dari rumusan masalah yang telah diungkapkan pada bab sebelumnya, bahwa dari hasil uji hipotesis dengan melakukan uji-t, ditemukan bahwa tidak terdapat pengaruh nyata dan signifikan antara variabel sistem manajemen SDM berbasis kompetensi terhadap kinerja karyawan. Hal ini dapat terlihat pada hasil uji-t diperoleh t-hitung sebesar 1,061, dengan tingkat probabilitas (sig) adalah 0,292. Jika dibandingkan pada ttabel pada $\alpha=0,05$, berarti t-hitung < ttabel dan sig > 0,05 $(1,061<1,669$ dan 0,292 > 0,05). Hal ini berarti bahwa hipotesis ditolak yaitu tidak terdapat pengaruh yang nyata dan signifikan antara variabel sistem manajemen SDM berbasis kompetensi $\left(\mathrm{X}_{1}\right)$ terhadap kinerja karyawan (Y) pada PT. Inducomp Dewata.

2. Dari hasil olah data pada hasil jawaban responden, ditemukanbahwa persepsi variabel penilaian prestasi kerja pada kategori baik. Hipotesis kedua yang diajukan oleh penulisbahwa terdapat pengaruh yang positif dan signifikan antara penilaian prestasi kerjaterhadap kinerja karyawan diterima. Hal ini dibuktikan dari hasil uji-t diperoleh thitung sebesar 7,263 dengan tingkat probabilitas (sig) 0,000. Jika dibandingkan pada t-tabel pada $\alpha=0,05$, berarti t-hitung $>$ t-tabel dan sig $<0,05$ $(\mathbf{7 , 2 6 3}>\mathbf{1 , 6 6 9}$ dan $0,000<\mathbf{0 , 0 5})$. Hal ini berarti bahwa hipotesis diterima yaitu adanya pengaruh positif dan signifikan antara variabel penilaian prestasi kerja $\left(\mathrm{X}_{2}\right)$ terhadap kinerja karyawan $(\mathrm{Y})$ pada PT. Inducomp Dewata, yang artinya jika menerapkan sistem penilaian prestasi kerja akan meningkatkan kinerja karyawan secara nyata.

3. Berdasarkan hasil perhitungan uji-F diperoleh bahwa F-hitungsebesar 26,991 dan sig 0,000, jika diselaraskan dengan F-tabelpada $\alpha=0,05 \mathrm{df} 1=2$, dan df $2=$ 70 diperoleh F-tabel sebesar 3,13. Hal iniberarti F-hitung > F-tabel dan sig < 0,005 $(26,991>3,13)$ dan sig $(0,000<$ $\mathbf{0 , 0 5})$ yang mengindikasikan bahwa hipotesis diterima. Hal ini berarti bahwa terdapat pengaruh yang nyata dan signifikan antara sistem manajemen sumber daya manusia bebasis kompetensi dan penilaian prestasi kerja 
Jurnal Satyagraha, Vol. 02, No. 02, Agustus 2019 - Januari 2020 ISSN :2620-6358

secarabersama-sama terhadap kinerja karyawan pada PT. Inducomp Dewata.Sistem manajemen SDM berbasis kompetensi banyak digunakan oleh perusahaan-perusahaan untuk merekrut karyawan yang akan bekerja. Dimana karyawan dituntut untuk memenuhi beberapa syarat sesuai dengan standar yang diinginkan oleh perusahaan. Dari hasil perekrutan itulah kemudian perusahaan akan menentukan apakah sesorang tersebut layak untuk bekerja di perusahaannya. Namun, karyawan saat perekrutan belum dapat dilihat kemampuannya sampai ia mulai bekerja. Maka dari itu perusahaan menerapkan sistem masa training dimana pada masa itu karyawan membutuhkan pelatihan dan evaluasi kinerja pertamanya, apakah karyawan tersebut mengalami kesulitan dalam hal memahami penjelasan ataupun dalam mengikuti pelatihan. Dari sini dapat dilihat bahwa sistem manajemen SDM berbasis kompetensi tidak bisa menentukan kinerja karyawannya hanya saja mampu mengevaluasi calon pekerja agar sesuai dengan yang dibutuhkan perusahaan.

Penilaian presatsi kerja diciptakan untuk melihat perkembangan kinerja karyawan serta dengan diadakannya penilaian prestasi kerja, karyawan akan termotivasi bersaing antar karyawan lainnya dalam hal meningkatkan kinerja untuk memperoleh nilai yang maksimal sehingga karyawan akan memiliki rasa puas akan hasil kerjanya. Tak hanya karyawan, perusahaanpun akan mendapatkan keuntungan baik dari segi sumber daya yang kompeten di bidang yang dibutuhkan maupun dari segi finansial, karena dengan kinerja karyawan yang baik maka secara tidak langsung akan memberikan timbal balik terhadap perkembangan perusahaan.

Dari hasil uji koefisien determinasi pengaruh yang diberikan darivariabel sistem manajemen SDM berbasis kompetnsi dan penilaian prestasi kerja secara bersama-sama terhadap kinerja karyawan sebesar $43,5 \%$, sedangkansisanya sebesar $56,5 \%$ kinerja karyawan dipengaruhi oleh variabel yangtidak menjadi fokus dalam penelitian ini.

\section{SIMPULAN DAN SARAN}

\section{Simpulan}

1. Penelitian ini membuktikan tidak adanya pengaruh antarasistem manajemen sumber daya manusia berbasis kompetensi terhadap kinerja karyawan (penelitian pada perusahaan pemperakitan di Kota Denpasar). Dengan menerapkan sistem ini terbukti tidak memberi pengaruh meningkatkan kinerja karyawan hanya saja dapat membantu perusahaan dalam proses perekrutan karyawan, sehingga membantu department yang membutuhkan karyawan untuk mengambil keputusan apakah karyawan tersebut memenuhi kriteria yang diinginkan atau tidak.

2. Penelitian ini membuktikan adanya pengaruh antarapenilaian prestasi kerja terhadap kinerja karyawan (penelitian pada perusahaanperakitan di Kota Denpasar). Dengan menerapkan sistem 
Jurnal Satyagraha, Vol. 02, No. 02, Agustus 2019 - Januari 2020 ISSN :2620-6358

penialain prestasi kerja yang diterapkan dengan model rating scale, terbukti meningkatkan kinerja karyawan, karena dengan melihat hasil kinerjanya, karyawan akan termotivasi untuk terus memperbaiki kinerja yang akan berpengaruh langsung terhadap gaji yang diterima. Karena semakin baik hasil penilaian karyawan yang diperoleh maka akan semakin besar pula gaji yang diterima.

3. Penelitian ini membuktikan adanya pengaruh antara sistem manajemen sumber daya manusia berbasis kompetensi dan penilaian prestasi kerja terhadap kinerja karyawan. Dengan melihat hasil perekrutan karyawan yang sudah memenuhi syarat perusahaan, perusaahaan hanya akan melatih karyawan tersebut yang kemudian mengevaluasi kinerjanya untuk pertimbangan-pertimbangan

kedepannya.

Saran

Adapun yang bisa peneliti sarankan kepada perusahaan PT. Inducomp Dewata, antara lain:

1. Hendaknya pihak-pihak yang terkait dalam perekrutan karyawan harus lebih teliti perihal peneriamaan karyawan, agar karyawan yang bekerja sudah sesuai dengan syarat yang diinginkan departemen terkait.

2. Hendaknya setiap kepala departemen mengevaluasi hasil penilaian kinerja bawahannya secara berkala dengan menggolongkan karyawan yang memiliki nilai rendah untuk langsung diberi pelatihan dan pembinaan ulang, kemudian karyawan yang memiliki nilai medium untuk dikembangkan keahliannya dan memberikan motivasi kepada karyawan yang memiliki nilai exellen agar tetap memberikan hasil kinerja yang terbaik untuk perusahaan.

3. Terkait dengan adanya beberapa reponden yang menyatakan bahwa mereka tidak setuju dalam hal diberikan keterbukaan memberi masukan, hendaknya perusahaan memberikan sarana untuk karyawan agar bisa memberikan ide-ide atau saran demi perbaikan perusahaan dan karyawan kedepannya.

\section{DAFTAR PUSTAKA}

Agustina Maarif, Fauzia. 2005. Analisis Hubungan Penilaian Kinerja Dengan Produktivitas Karyawan (Studi Kasus pada Sub Divisi Group Liabilities Consumer Banking PT. Bank Bukopin Jakarta. Skripsi Manajemen Fakultas Ekonomi. Institut Pertanian Bogor.

Amin, Namira Mardin. 2015. Pengaruh Kompetensi Terhadap Kinerja Pegawai Pada Sekretariat Daerah Kabupaten Sidenreng Rappang. Skripsi Jurusan Ilmu Administrasi. Universitas Hasanudin.

Andriani, Yuni.2018.Pengaruh Penilaian Prestasi Kerja Karyawan Terhadap Promosi Jabatan Pada PT. Noor Asni Naga Jaya (RAYON ILIR) Samarinda.Journal Administrasi Bisnis 6(1): 90-101 Issn 2355-5408 
Jurnal Satyagraha, Vol. 02, No. 02, Agustus 2019 - Januari 2020 ISSN :2620-6358

Aprilda, 2012.Pengaruh Kompetensi Terhadap Prestasi Kerja PegawailStudi Pada Bagian Pengelolaan Keuangan Balai Pengembangan Pendidikan Nonformal Dan Informal Regional I Medan).Jurnal Administrasi Publik Vol. 3 No. 2 Hal. 181 - 206.

Elfianto.(2014). Pengaruh Penilaian Prestasi Kerja Pegawai terhadap Promosi Jabatan Pegawai di BPS Provinsi Sumatera Barat.Universitas Tamansiswa Padang. Jurnal Manajemen.

Hasanah, Selvi Usrotul; Budi Nurhardjo; Sampeadi. (2014). Pengaruh Kompetensi Dan Sistem Penilaian Prestasi Kerja Terhadap Kinerja Melalui Pengembangan Karir Bagi Penyuluh Keluarga Berencana Pada Kantor Keluarga Berencana Di Kabupaten Situbondo.Artikel Ilmiah Mahasiswa jurusan Manajemen. Universitas Jember.

Hasibuan, Malayu S P. 2014. Manajemen Sumber Daya Manusia Edisi Revisi. Jakarta: PT.Bumi Aksara

Hidayati, Ismania, Endang Siti Astuti, and Muhammad Iqbal. 2014. Analisis Penerapan Sistem Manajemen Kinerja Berbasis Kompetensi (Studi Pada PT. Petrokimia Gresik). Jurnal Administrasi Bisnis 15 (1):1-5.
Juita ,Riska. (2016). Pengaruh Penilaian Prestasi Kerja Dan Kompetensi Karyawan Terhadap Promosi Jabatan Pada PT. Suka Fajar Ltd Bangkinang. Skripsi Manajemen. Universitas Islam Negri Sultan Syarif Kasim Riau.

Kadarisman, 2013.Manajemen Pengembangan Sumber Daya Manusia. Jakarta: PT. Raja Grafindo Persada.

Kosnanjar, Yaumi Tegar.2017.Implementasi Manajemen Sumber Daya Manusia Berbasis Kompetensi Dalam Upaya Meningkatkan Kualitas Kerja Pegawai Kementrian Agama Kabupaten Bantul.Skripsi Manajemen Pendidikan Agama Islam.Universitas Islam Negri Sunan Kalijaga Yogyakarta.

Kusumastuti, Dyah. 2010. "Reformasi Birokrasi dengan Implementasi Manajemen Sumber Daya Manusia Berbasis Kompetensi." Jurnal Administrasi Pemerintah Daerah 1 (1): 31-40.

Mayasari, Isti, Hariyani Kristiana, and Hindiarto Ferdinandus. 2012. "Penilaian Kinerja Berdasarkan Kompetensi dan KPI (Kompetensi Performer Indikator) Daerah Air 
Jurnal Satyagraha, Vol. 02, No. 02, Agustus 2019 - Januari 2020 ISSN :2620-6358

Minum Kabupaten Semarang." Kajian Ilmiah Psikologi 227.

Nurjannah, Siti. (2016). Pengaruh Kompetensi dan Insentif Terhadap Prestasi Kerja Karyawan pada Kantor Pelayanan III Perusahaan Daerah Air Minum (PDAM) Kota Makassar.Skripsi Manajemen Universitas Islam Negri Makassar.

Pramularso, Eigis Yani. 2018. Pengaruh Kompetensi terhadap Kinerja Karyawanpada CV Inaura Anugerah Jakarta. Jurnal Manajemen. Volume 2 No.1

Priansa, Donni Juni. 2016. Perencanaan dan Pengembangan SDM. Edisi Kedua. Bandung: Alfabeta.

Rani, Indria Hangga, Mega Mayasari. 2016.Pengaruh Penilaian Kinerja Terhadap Kinerja Karyawan Dengan Motivasi Sebagai Variabel Moderasi Pada Perusahaan Manufaktur Industri Elektronik Di Batam. Jurnal Manajemen Bisnis Politeknik Negeri Batam.

Riyanda, Muhammad. 2017. Pengaruh Kompetensi Dan Disiplin Kerja TerhadapKinerja Pegawai Pada Dinas PerizinanKota Yogyakarta.Skripsi Manajemen Universitas Negri Yogyakarta.
Setiyono. 2015. Pengaruh Sistem Manajemen SDM Berbasis Kompetensi dan Penilaiai Prestasi Kerja terhadap Kinerja Pegawai PTPN IX Semarang. Jurnal Manajemen Volume 1 No. 1.Universitas Pandanaran Semarang.

Sholehatusya'diah. 2017. Pengaruh Kompetensi Kerja terhadap Kinerja Karyawan Di Kantor PT. Kitadin Tenggarong Seberang.Jurnal Administrasi Negara Volume 5, (Nomor 2) 5789 -5802 Universitas Mulawarman.

Silaban , Fikky Chandra. (2016). Pengaruh Kompetensi Dan Penilaian Prestasi Kerja Pegawai Terhadap Promosi Jabatan Pada Badan Penyelenggara Jaminan Sosial (BPJS) Kesehatan Cabang Pematangsiantar.Jurnal Manajemen Volume.5, No. 2.

Undang-undang Negara Republik Indonesia No. 13 Tahun 2003 TentangKetenagakerjaan.

Umar, Husein. 2003. Evaluasi Kinerja Perusahaan. Jakarta: Gramedia Utama

Wijaya, R. M. (2009). Pengaruh Komitmen Organisasi Dan Penilaian Kinerja Terhadap Kepuasan Kerja pada Karyawan Bagian Bengkel PT. PAL 
Jurnal Satyagraha, Vol. 02, No. 02, Agustus 2019 - Januari 2020 ISSN :2620-6358

di Surabaya. Surabaya: Sekolah

Tinggi Ilmu Ekonomi Perbanas.

Yani, H.M. 2012. Manajemen Sumber daya

Manusia. Jakarta: Mitra Wacana Media. 